\title{
The Impact of Breast Cancer Educational Workshop on Knowledge and Breast Self-Examination Practice Among Korean-American Women
}

\section{Corinne $\mathrm{Lee}^{1^{*}}$ and Tsu-Yin $\mathrm{Wu}^{2}$}

${ }^{1}$ Educational Nurse Specialist, University of Michigan Health System, Ann Arbor, MI, USA

${ }^{2}$ Professor, Eastern Michigan University, Ypsilanti, MI, USA

*Corresponding author: Corinne Lee, University of Michigan Health, Ann Arbor, MI, USA, Tel: 1-734-763-5283; E-mail: leeco@med.umich.edu

Received date: April 24, 2014, Accepted date: June 30, 2014, Published date: July 2, 2014

Copyright: $(2014$ Lee C, et al. This is an open-access article distributed under the terms of the Creative Commons Attribution License, which permits unrestricted use, distribution, and reproduction in any medium, provided the original author and source are credited.

\begin{abstract}
Among Korean-American women, breast cancer is the second leading cause of death. Although the incidence is lower than that of Caucasian women, Korean-American women are more likely to be diagnosed at more advanced stages of breast cancer. Among the suggested methods in breast-cancer prevention are early detection and routine screenings. The present study was conducted to explore the impact of breast-cancer educational workshops on breast-cancer knowledge and breast self-examination (BSE) practices among Korean-American women. Knowledge of breast cancer and health beliefs (perceived benefits, perceived barriers, and perceived self-efficacy) were examined before and after the educational workshop. The results indicated that educational workshops have a positive influence on breast-cancer knowledge, health beliefs, and the intent to practice BSE in the future.
\end{abstract}

Keywords: Breast cancer; Educational Workshop; Korean-American Women

\section{Introduction}

\section{Breast cancer: incidence and early detection}

According to the American Cancer Society (ACS) [1], breast cancer is the second most frequently diagnosed cancer among women. The number of diagnosed cases each year increased from 1994 to 1999 and decreased 2.0\% each year from 1999 to the present. Even though breast cancer is the second leading cause of cancer deaths among American women, the death rate due to breast cancer has been decreasing since the 1990s. In the 1960s, the five-year survival rate was 63\%; in 2010, the five-year survival rate increased to $90 \%$ with $98 \%$ for the localized stage (stage I) of breast cancer [1]. According to the ACS and the National Cancer Institute, the decrease in the incidence rate, especially in the later stages (Stage III and up), and the increase in the five-year survival rate are related to early detection and the public's breastcancer awareness $[1,2]$.

In Korea, the statistics from the National Cancer Information Center in Korea showed that breast cancer is the fifth leading cause of cancer deaths among Korean women (7.5\%). There was a slow increase from 5,703 newly diagnosed cases in 1999 to 15,942 in 2011, making breast cancer the second largest diagnosed cancer in Korea in 2011 , which accounts for $14.8 \%$ of all female cancers. The five-year survival rate, however, has increased from $78.0 \%$ in 1995 to $91.3 \%$ in $2011[3]$.

According to the National Cancer Institute Surveillance, Epidemiology and End Results program (SEER), Asian-PacificIslander women have one of the lowest breast-cancer incidence rates in the U.S. In 2010, the incidence of breast cancer among Caucasian women living in the U.S. was 118.7 per 100,000 and for Asian-PacificIslander women living in the U.S. was 85.8 per 100,000 [4]. In 2011, incidence of breast cancer for Korean women living in Korea was 63.7 per 100,000 [3]. The mortality rate in 2010 was 21.3 for Caucasian women and 11.7 for Asian-Pacific-Islander women per 100,000. In addition, similar to Caucasian women, the second leading cause of cancer deaths among Asian-Pacific-Islander women living in America is due to breast cancer [4].

Although Asian-Pacific-Islander women, including Korean women, have a lower incidence rate than Caucasian women, comparing the ratio between the incidence rate and the death rate, they are more likely to be diagnosed at later stages (Stage III and up). Research has shown that early detection has played an important role in reducing the incidence of cancers detected at later stages $[4,5]$.

It has been widely shown that one of the most effective factors associated with decreasing the incidence rate and increasing the fiveyear survival rate in breast cancer is early detection. National organizations, including the ACS and the Korean Breast Cancer Society, suggest breast self-examination (BSE; every month from 20 years old and up), breast-cancer awareness (for all ages), clinician breast examination (every 2-3 years from 20-39 years old, annually from 40 years old and up), and mammogram (annually from 40 years old and up) as the early detection methods $[6,7]$.

Breast-cancer awareness, suggested for all ages, is defined as knowledge about breast health and breast cancer as well as that about breast-cancer screening. This is important because the more knowledgeable women are about breast cancer, the lower the mortality rate of breast cancer [8,9]. Moreover, several research studies have shown that early detection due to screening and awareness programs has led to a decrease in the incidence rate of later stages in breast cancer and an increase in the five-year survival rate [6,7].

In Korea, the breast-cancer awareness campaign (BCAC) started in the mid-1990s. Organizations, such as the Korean Cancer Society, the Korean Oncology Nursing Society, and the Korean Breast Cancer Foundation, have promoted the public's awareness of breast cancer. The incidence of breast cancer increased in Korean women from 1999 to 2011; nevertheless, the five-year survival rate showed an increase of 
$13.3 \%$ in the same period, which may be related to the BCAC. Due to these campaigns, more women are being diagnosed at earlier stages of breast cancer, and the five-year survival rate has become higher. The cases of early stage (i.e., stage I) increased from $37.9 \%$ in 2006 to $39.1 \%$ in 2010 , whereas later stage (i.e., stage III) decreased from $14.4 \%$ in 2006 to $11.8 \%$ in 2010 [5].

\section{Educational strategies to promote awareness and screening}

Several strategies have been used in the BCAC, such as health fairs, breast-cancer workshops, free breast clinics, and fund-raising events to promote breast-health awareness and breast-cancer screening. Among them, education is the most frequently used component: teaching women about the signs and symptoms of breast cancer and such early detection methods, as the BSE, clinician breast exam, and mammograms $[7,8,10,11]$. Breast-cancer workshops and educational programs often include presentations on risk factors and statistics on breast cancer and the importance of early detection through screening. Additionally, they may also include the BSE demonstration and practice on a simulated breast model [9-13].

A number of studies have demonstrated that breast-cancer knowledge has positively influenced the behavior or practice of early detection in breast cancer among Korean-American and Korean women [9-11,14]. Also several studies have been conducted to determine the effects of education about breast cancer among such other ethnic groups as Turkish women, African-American women, and Chinese-American women. All of the results revealed an increase in the knowledge of the participants and their health-seeking behaviors $[8,12,13]$.

Although many studies have examined the influence of educational programs about breast cancer on health behaviors and early detection practices, few studies were found among Korean-American women. Furthermore, in an earlier descriptive correlational study, language was identified as an important barrier because the education and information given were in English. Therefore, this study, due to the language and cultural barriers, recommended that educational programs be done in the targeted audience's native language [14].

\section{Purpose}

The purpose of the study was to explore the impact of breast-cancer educational workshops conducted in Korean on breast-cancer knowledge and breast self-examination practices among KoreanAmerican women. This study was conducted to provide additional information to the body of nursing knowledge on prevention of breast cancer by increasing knowledge and promoting healthy behaviors, such as recommended screenings for breast cancer, among KoreanAmerican women.

\section{Materials and Methods}

\section{Theoretical framework}

The Health Belief Model (HBM) guided the study. Originally in the HBM there were four concepts among individual beliefs: 1) Perceived susceptibility (the individual's opinion of the likelihood of getting an illness), 2) Perceived severity (the individual's opinion of the seriousness regarding an illness and its consequences), 3) Perceived benefits (the individual's belief in facilitating the advised action to decrease the risk or severity of an illness), 4) Perceived barriers (the individual's opinion of the costs in taking the advised action). In the 1990s, two more concepts were added, 5) Cues to action (factors to motivate an individual's readiness to change) and 6) Self-efficacy (confidence in the individual's capability to take the advised action) $[10,15,16]$.

According to the HBM, six modifying factors directly affect an individual's health beliefs. They are the individual's age, gender, ethnicity, personality, socioeconomic status and specific knowledge related to the issue. These factors also influence an individual's health behaviors indirectly [17].

Several studies have been conducted to examine HBM variables in breast-cancer screening behaviors among various ethnic groups, and scales and tools were developed based on HBM conceptual definitions for assessing and measuring a patient's need. In particular, the Champion HBM Scale was developed to assess the knowledge and performance of BSE according to the concepts in HBM $[15,18]$. Another instrument is the Asian-American Women Mammogram Screening Beliefs Questionnaire by $\mathrm{Wu}$ and $\mathrm{Yu}[19]$ and $\mathrm{Wu}$ and Ronis [20], which was developed and texted to assess the barriers and beliefs on mammogram screening among Asian-American women.

In this study, the researchers focused on one of the modifying factors (knowledge), and on three individual beliefs (perceived benefits, perceived barriers, and self-efficacy), and their effects on an individual's health behavior (shown in bold on Figure 1). The study instrument was modified from the Champion's HBM scale and Wu's Asian-American Women Mammogram Screening Beliefs Questionnaire.

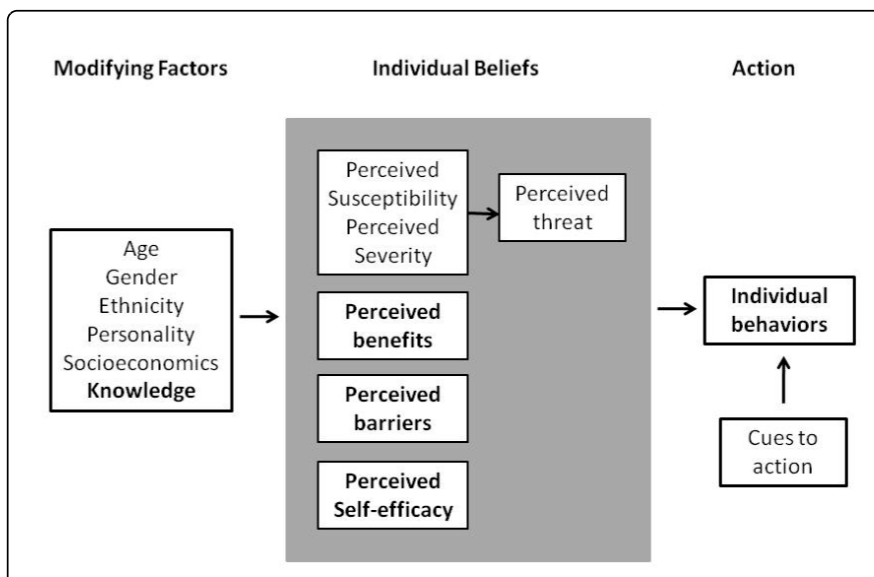

Figure 1: Health Belief Model: Glanz, Rimer, \& Viswanath, 2008, p. 49

\section{Study design}

This study used a one-group pretest-posttest pre-experimental design. This design enables examining the effectiveness of the treatment by comparing the scores between the pretest and posttest of the same group of subjects [21]. Moreover, because the pretest and posttest were given and collected in the same setting, there is a higher chance of receiving all the responses of both tests. For higher response rate on surveys, the evidence recommended collecting surveys when the attention of the participants is captured [21]. Additionally, having the participants turn in the survey in order to collect their incentive would contribute to the higher response rate. 


\section{Sampling}

Convenience sampling was used in the study. Fifty KoreanAmerican women in Washtenaw County, Michigan, participated in the study in three separate workshops. The workshops were publicized by placing flyers at various places where Korean-American women were likely to frequent, such as grocery stores, churches, and restaurants in Ann Arbor and Ypsilanti, Michigan. The flyer contained information on the workshops along with the investigator's name and the supervising faculty's contact information. At the workshops, the women were asked to participate in the study. The inclusion criteria were: 1) All participants were women who self-identified as KoreanAmerican; 2) Since the workshops were given in Korean, the participants had to be able to comprehend the language in both spoken and written format; and 3) Participants were 18 years of age or older. Four surveys were excluded because the participants arrived late for the workshop-almost towards the end of the presentation.

\section{Instrumentation}

The study questionnaire was adapted from the Asian-American Mammogram Screening Beliefs Questionnaire (reliability tested with the Cronbach's alpha, which ranged from 0.75 to 0.90 and validity supported by confirmatory factor analysis) by $\mathrm{Wu}$ and $\mathrm{Yu}$ [19] and the Champion's Health Belief Model Scale (reliability tested with the Cronbach's alpha, which ranged from 0.80 to 0.93 , and validity was supported by confirmatory factor analysis) related to breast cancer and BSE by Champion [22]. Both instruments included study variables based on the HBM $[19,22]$. The reliability of the instruments used in the study was tested using the Cronbach's alpha (0.82 to 0.91 ; Table 1$)$.

\begin{tabular}{|l|l|l|}
\hline & No. items & Cronbach's $\alpha$ \\
\hline Knowledge of breast-cancer risk & 8 & 0.82 \\
\hline $\begin{array}{l}\text { Knowledge of recommendations for } \\
\text { frequency of mammogram and BSE }\end{array}$ & 10 & 0.91 \\
\hline $\begin{array}{l}\text { Knowledge of recommendations for } \\
\text { frequency of BSE }\end{array}$ & 5 & 0.90 \\
\hline Perceived benefits & 6 & 0.90 \\
\hline Perceived barriers & 6 & 0.85 \\
\hline Perceived self-efficacy & 7 & 0.89 \\
\hline
\end{tabular}

Table 1: Reliability of the Instruments

The adapted study tool contained a total of 51 questions that measure the major concepts of HBM: the demographicscharacteristics of the participants (eight items), the knowledge of participants on breast-cancer screenings (five items), breast-cancer risks (eight items), recommendations for frequency of mammography (five items) and BSE screenings (five items), health beliefs on perceived benefits (six items), perceived barriers (six items) and selfefficacy (seven items). Additionally, there was one item on the participants' BSE behavior (frequency).

In the study, HBM constructs related to beliefs (i.e., perceived benefits, barriers, and self-efficacy) were measured by a 5-point Likert scale (strongly agree, agree, neutral, disagree and strongly disagree). The total score for the three health-beliefs constructs were added and ranged from 19 to 95 . The knowledge was measured using multiplechoice questions with five different choices and one correct answer.
The total score for the knowledge was summed up and ranged from zero to 23 . The questionnaire took approximately 10-20 minutes to complete. The participants self-completed the questionnaire in Korean.

\section{Study procedures}

Three workshops were scheduled between May and July 2011. At the workshops, a pretest was administered to examine the participants' knowledge, beliefs, risks, perceived benefits, perceived barriers and self-efficacy of breast cancer and breast-cancer screenings. After the pretest, a PowerPoint lecture on breast cancer and breast-cancer screening was provided for the participants. Following the lecture, a demonstration and a practice session on BSE were provided using a breast model. The Power Point lecture and the BSE session were developed with the information from Susan G. Komen, the ACS, and the Korean Breast Cancer Society by the investigator. The latest evidences and recommendations on practice were gathered and put together. An expert on breast-cancer prevention validated the information. The investigator presented the lecture and the BSE demonstration in Korean. Handouts, such as a door hanger with the instructions on the BSE practice in Korean developed by Susan G. Komen for the Cure and a brochure in Korean that provides information related to breast health specifically targeted to Asian women developed by the investigator. Additionally, a clinical breast examination $(\mathrm{CBE})$ by a women's health-nurse practitioner was offered to all participants who are interested in getting a CBE. Following the $\mathrm{CBE}$, a posttest was administered to examine any changes in the participants' knowledge, perceived benefits, perceived barriers, and self-efficacy of breast cancer. A $\$ 10.00$ gift certificate was given to all the participants who completed the study to thank them for their participation.

\section{Data analysis}

The questionnaires were analyzed using the Statistical Package for the Social Sciences (SPSS) software program, version 19.0 (SPSS Inc., Chicago, IL). The reliability of the instruments used was analyzed using Cronbach's alpha. A descriptive analysis was used for the characteristics of the participants. Moreover, the bivariate correlational analysis was used to measure the relationship between breast-cancer knowledge and the BSE practices. The bivariate correlational analysis was also used to measure the relationship between breast-cancer knowledge and health beliefs (perceived benefits, perceived barriers, and perceived self-efficacy). Pair T-tests were used to determine the influence of the educational workshop on breast-cancer knowledge and health beliefs. It was also used to determine the differences between breast-cancer knowledge and the BSE practices with the gathered data.

\section{Ethical considerations}

Approval was sought and granted prior to initiating the study through the Human Subjects Review Committee of Eastern Michigan University. Participation in the study was on a voluntary basis. An informed consent form was provided for the participants. The consent detailed the title, purpose, procedure, benefits, risks and confidentiality of the study was translated into Korean for the study. The translated consent form was back-translated into English by another translator to ensure the accuracy of the information. The translator was fluent in Korean and English in both speech and writing. 
Page 4 of 7

In order to ensure the confidentiality of the participants, no questions required personal identifying information. The questionnaires were coded by the workshop: Workshop \#1, \#2, and \#3. In order to differentiate the questionnaires from the pre-test and the post-test, the pre-test was printed on white paper and the post-test was printed on yellow paper. The collected data were stored in a secured place and were only accessed by the researchers.

\section{Results}

\section{Demographic characteristics of the sample}

Participants were 50 Korean-American women. All the participants completed their questionnaires for pre-test and post-test. The ages of the participants ranged from 20 to 81 years, with a mean of 46.5 $(\mathrm{SD}=18.50)$. There were 19 participants $(38 \%)$ under the age of 40 years, and $30(60 \%)$ were 40 years or more. One participant did not give her age $(2 \%)$. The mean number of years the participants have resided in the U.S. was 17.5 years. Of all the participants, $38 \%(n=19)$ stated that their stay in the U.S. was five years or less, $20 \%(n=10)$ was between six and fifteen years, $40 \%(n=20)$ was more than 16 years, and $2 \%(\mathrm{n}=1)$ were born in the U.S. Most of the participants finished their education in university/college or higher $(68 \% ; n=34)$. Eighteen participants were housewives (36\%), 11 students (22\%), 6 retirees (12\%), and 2 teachers (4\%). Most of the participants had U.S. health insurance $(86 \% ; n=43)$. Additionally, $26(52 \%)$ stated that they had been diagnosed with breast cancer. Within that 26 women, $15(57.7 \%)$ stated that they were diagnosed with breast cancer one year ago or less. Thirteen (26\%) stated that they have a family history of breast cancer. Most of them stated that it was their mother who was diagnosed with breast cancer $(n=7 ; 53.8 \%)$. Twenty-two stated that a close friend was diagnosed with breast cancer (Table 2).

\begin{tabular}{|c|c|c|c|}
\hline Variable & $\mathbf{n}$ & $\%$ & Mean \pm SD \\
\hline \multicolumn{4}{|l|}{ Age } \\
\hline Under 40 years & 19 & 38 & \\
\hline 40 years or more & 30 & 60 & \\
\hline Missing & 1 & 2 & $46.53 \pm 18.50$ \\
\hline \multicolumn{4}{|c|}{ Years of resident in U.S } \\
\hline $0-5$ years & 19 & 38 & \\
\hline $6-15$ years & 10 & 20 & \\
\hline $16+$ years & 20 & 40 & $17.41 \pm 16.74$ \\
\hline U.S. born & 1 & 2 & \\
\hline \multicolumn{4}{|l|}{ Education } \\
\hline High School & 15 & 30 & \\
\hline University/College & 29 & 58 & \\
\hline Graduate Studies & 5 & 10 & \\
\hline Missing & 1 & 2 & \\
\hline \multicolumn{4}{|l|}{ Occupation } \\
\hline Housewife & 18 & 36 & \\
\hline
\end{tabular}

Table 2: Characteristics of the Participants $(n=50)$.

* Participants who were 40 years and older

\section{Knowledge and practice of breast-cancer screenings}

Most of the participants in the study reported that they have heard of mammograms $(78 \% ; n=39)$ and BSE $(84 \% ; n=42)$. Their knowledge, however, about when to start the annual mammogram was low (16\%; $\mathrm{n}=8$ ). Similarly, the actual knowledge on the recommended frequency of BSE was low $(36 \% ; n=18)$. The survey question about the practice of mammogram was targeted to those who were 40 years of age and older $(\mathrm{n}=32)$. The participants who reported practicing the mammogram annually as recommended was $50 \%(n=16)$. The question about practicing the recommended monthly BSE was for all the participants; the BSE practice was $6 \%(n=3$; Table 2$)$.

\section{The influence of educational workshop on the study variables}

After the workshop, the levels of mean scores for the knowledge of the frequency of mammogram and BSE, perceived benefits, and selfefficacy increases and the perceived barriers' mean scores decreases (Table 3). The comparison between the pre-test and the post-test knowledge of breast-cancer risk and recommendations for screenings (mammogram and BSE) showed a significant increase ( $\mathrm{p}$ value $<.001$ ). In addition, after the educational intervention, participants increased their knowledge on breast health, perceptions on benefits of, barriers 
toward, and self-efficacy of breast-cancer screening (all the $\mathrm{p}$ values<.

001; Table 3).

\begin{tabular}{|c|c|c|c|c|c|}
\hline & & $\mathbf{n}$ & Mean $\pm S D$ & $t$ value & p value \\
\hline \multirow[t]{2}{*}{ Knowledge of breast-cancer risk } & Pre-test & 50 & $3.20 \pm 1.91$ & \multirow[t]{2}{*}{-10.544} & \multirow[t]{2}{*}{.000} \\
\hline & Post-test & 50 & $6.86 \pm 1.33$ & & \\
\hline \multirow[t]{2}{*}{ Knowledge of recommendations for frequency of mammogram \& BSE } & Pre-test & 50 & $3.60 \pm 3.33$ & \multirow[t]{2}{*}{-9.495} & \multirow[t]{2}{*}{.000} \\
\hline & Post-test & 50 & $8.42 \pm 2.04$ & & \\
\hline \multirow[t]{2}{*}{ Perceived benefits } & Pre-test & 50 & $20.58 \pm 5.22$ & \multirow[t]{2}{*}{-5.336} & \multirow[t]{2}{*}{.000} \\
\hline & Post-test & 50 & $24.98 \pm 3.03$ & & \\
\hline \multirow[t]{2}{*}{ Perceived barriers } & Pre-test & 50 & $23.54 \pm 4.39$ & \multirow[t]{2}{*}{-3.069} & \multirow[t]{2}{*}{.000} \\
\hline & Post-test & 50 & $26.10 \pm 4.07$ & & \\
\hline \multirow[t]{2}{*}{ Perceived self-efficacy } & Pre-test & 50 & $16.44 \pm 6.03$ & \multirow[t]{2}{*}{-11.251} & \multirow[t]{2}{*}{.000} \\
\hline & Post-test & 50 & $29.20 \pm 4.57$ & & \\
\hline
\end{tabular}

Table 3: Knowledge of Breast-Cancer Risk, Knowledge of Recommendations for Frequency of Mammogram and BSE, Perceived Benefits, Perceived Barriers and Perceived Self-Efficacy.

\section{Relationships between breast-cancer knowledge and BSE practices}

An independent $\mathrm{t}$-test was performed on the knowledge score between those who practiced BSE as recommended $(\mathrm{n}=3$, mean $=5.33$ $\pm 4.73)$ and those who did not $(n=47$, mean $=6.89 \pm 4.50)$. The results showed no significant differences $(\mathrm{t}=-0.581, \mathrm{p}$-value=.564). It is interesting to note that the knowledge score is higher in the group who did not practice BSE.

\section{Relationships between breast-cancer knowledge and health beliefs}

The relationships between the knowledge of breast cancer and the health beliefs (perceived benefits, perceived barriers, and perceived self-efficacy) were examined through Pearson Correlation. The results showed that the participants who have higher knowledge scores also show higher levels of perceived benefits $(\mathrm{r}=.387, \mathrm{p}=.006)$ and perceived self-efficacy $(\mathrm{r}=0.445, \mathrm{p}=0.001)$. No significant relationship exists between breast-cancer knowledge and the perceived barriers $(r=0.253$, $\mathrm{p}=0.077$; Table 4).

\begin{tabular}{|l|l|l|l|l|}
\hline & & $\begin{array}{l}\text { Perceived } \\
\text { benefits }\end{array}$ & $\begin{array}{l}\text { Perceived } \\
\text { barriers }\end{array}$ & $\begin{array}{l}\text { Perceived } \\
\text { self- } \\
\text { efficacy }\end{array}$ \\
\hline $\begin{array}{l}\text { Breast- } \\
\text { cancer } \\
\text { knowledge }\end{array}$ & $\begin{array}{l}\text { Pearson } \\
\text { correlation }(r)\end{array}$ & 0.387 & 0.253 & 0.445 \\
\cline { 2 - 5 } & $p$ value & 0.006 & 0.077 & 0.001 \\
\cline { 2 - 5 } & $\mathrm{N}$ & 50 & 50 & 50 \\
\hline
\end{tabular}

Table 4: Correlation of Breast-Cancer Knowledge and Perceived Benefits, Perceived Barriers and Perceived Self-Efficacy.

\section{Influence of the educational workshop on future bse practices and health-promoting behaviors}

Before the workshop, the participants were asked in the questionnaire about their BSE practices. Only three answered that they were performing monthly BSE as recommended. Following the PowerPoint presentation on breast cancer and early detection, the participants were asked about the recommendation of all the early detection methods and its timings. Eighty percent of the participants gave a correct oral response of their understanding of the early detection methods and timings. This was again reinforced by the nurse practitioner during the clinical breast examinations. All the participants opted to receive CBEs after the educational intervention.

\section{Discussion}

The results of this study confirm that the breast-cancer educational workshop had a positive influence on the Korean-American women's knowledge about breast cancer and early detection, as well as the health beliefs: perceived benefits, perceived barriers, and perceived self-efficacy $[9-11,14]$.

It also suggests that a significant relationship exists between breastcancer knowledge and perceived benefits. Many participants stated that they did not realize the importance of BSE and practicing it monthly. When the knowledge of breast cancer was low, the women failed to recognize the benefits of BSE. This was reiterated at the end of the workshop.

The study also demonstrated a significant relationship between breast-cancer knowledge and perceived self-efficacy. The lower the breast-cancer knowledge, the lower the confidence in BSE practice, which may indicate that the women were less likely to practice BSE unless they knew the correct way of performing BSE.

On the contrary, no significant relationship exists between breastcancer knowledge and perceived barriers. This finding is consistent with that observed in the previous study conducted by Lee, Lee, Shin, 
and Song [10]. The absence of any significant relationship between them may be attributed to the social-cultural background rather than the simple change of knowledge, as suggested by these investigators $[10]$.

The workshops were given in Korean. The language is in fact one of the important barriers to the access of care [14]. The first workshop flyer that was distributed to the community included only the English names in the contact-information section. Although ten women were present in the workshop, none had attempted to contact the investigator. For the flyers for workshops \#2 and \#3, the investigator's Korean name was given on the flyers. Several of the women who participated in the workshops contacted the investigator for more information on the workshop. The workshops were also conducted in Korean. More than half of the participants confirmed that since there was a Korean name on the flyer, they felt more comfortable contacting and participating in the workshop.

More than 15 participants stated that when they knew someone, whether a family member or a friend, was diagnosed with breast cancer they were more aware of health-seeking behaviors and had a willingness to learn. Moreover, they added after the workshop that they would like to share what they have learned and encourage others to join the workshops. These results are consistent with those of Sadler et al. [14] on the women's willingness to learn and share information through educational programs.

One of the surprising results found in the study was the higher percentage of Korean-American women participants who reported being diagnosed with breast cancer $(n=26 ; 52 \%)$; this may have triggered their interest in attending the workshop. On the other hand, this may well have been a misunderstanding of the question "Have you ever been diagnosed with breast cancer?" Some indeed answered "yes" for this particular question and answered "no" to "Have you ever heard of mammogram" or "never" to "When was your last mammogram done?" They could have misunderstood. The investigator was not able to verify this issue with follow-up because the questionnaires did not contain any identification or contact information about the participants. In future studies, the researchers should clarify and verify the response for the question regarding the diagnosis of breast cancer on site when there are face-to-face opportunities for verification.

Some of the previous studies suggested embarrassment as a frequently identified barrier [9-11]. Embarrassment, however, was identified by only $12 \%$ of the women $(n=6)$ in the study as a potential barrier to screening. This may be related to the fact that everyone participated in the clinician breast examination after the PowerPoint lecture. They actually wanted to learn more information about breast cancer and to seek follow-up screening.

The relationship between breast-cancer knowledge and BSE practices was not positive. This was somewhat different from previous study results where, when the knowledge was high, health-seeking behaviors, such as breast-cancer screenings, increased [8-14]. This study's result might have been affected by the fact that there were very few participants who practiced BSE $(n=3)$. Additionally, there was no follow-up on the participants for their future practices. The increase of perceived self-efficacy, however, after the educational workshop might be an indicator for BSE practices in the future. Moreover, the comments after the workshop suggested they would now practice monthly BSE since they knew the importance and steps of BSE.

\section{Limitations and future research recommendations}

The study has a few limitations. First of all, the number of KoreanAmerican women in the area was relatively small. It has been suggested that the biases of the convenience sampling can be reduced with a larger number of participants [17]. Due to the limited number of Korean-American women in the area, there were not enough subjects to create separate experimental and comparison groups. Thus, one-group pretest-posttest pre-experimental design was used. This may have resulted in slightly weaker validity than that in those studies using experimental design with a control group and randomization [21]. Additionally, the study lacked a follow-up on these women to evaluate their future practices of BSE. This was in part due to the issue of confidentiality, so that there was no identifying information on the participants. In future studies, there should be follow-up, either with phone or mail surveys, on the BSE practices of the participants. Another limitation was that some of the participants might have misunderstood the meaning of the question on "Have you ever been diagnosed with breast cancer?" This needed to be clarified during the workshop.

Through this study, it was demonstrated that education, such as workshops, is important in increasing breast-cancer knowledge, which may promote breast-cancer screenings. It should be noted that culturally specific and language-sensitive education may have the largest impact on behavior changes. Health care professionals, nurses in particular, can be educated on the special needs of Korean women in terms of their knowledge levels and perceptions toward breast cancer, BSE, and other screening practices so they can assist women in mastering these health behaviors. Educational resources are available in many languages and should be used for programming.

The positive results on the knowledge and the individual's healthbeliefs about breast cancer after the educational workshops in the current study indicate that the format of such educational interventions may be applicable in promoting breast-cancer awareness and early-detection screenings. These workshops have shown to be effective in various cultural groups and can be used as a strategy to promote health in these ethnic communities.

Study designs using both comparison and experimental groups with more participants are needed to further evaluate the relationship between knowledge and practice of BSE. Moreover, a follow-up at three months to a year is needed to determine the efficacy of early detection screenings, such as BSE and mammogram, and healthpromoting behaviors [22].

In conclusion, despite the limitations of the study, the workshop had a positive influence on breast-cancer knowledge and health beliefs among Korean-American women. The cultural considerations, such as the workshop being presented in Korean, was an added advantage on the value of the workshop.

\section{Acknowledgement}

This project was partially supported by the Susan G. Komen for the Cure Mid-Michigan Affiliate. The authors extend their appreciation to all the women who attended the workshops for their participation and support.

\section{References}

1. American Cancer Society (2010) Cancer facts and figures 2010. 
Citation: Lee C, Wu TY (2014) The Impact of Breast Cancer Educational Workshop on Knowledge and Breast Self-Examination Practice Among Korean-American Women. J Nurs Care 3: 176. doi:10.4172/2167-1168.1000176

Page 7 of 7

2. National Cancer Institute (2010) The Surveillance Epidemiology and End Results (SEER) cancer statistics review, 1975-2007.

3. National Cancer Information Center in Korea. (2013) Cancer facts \& figures 2013 in the Republic of Korea.

4. Howlader N, Noone A, Krapcho M, Garshell J, Miller D, et al. (2013) SEER Cancer Statistics Review, 1975-2011, National Cancer Institute. Bethesda, MD

5. Korean Breast Cancer Society (2013) Breast cancer encyclopedia, 2013.

6. Korean Cancer Society (2007) Fourteen rules on cancer for patients and families.

7. Smith RA, Saslow D, Sawyer KA, Burke W, Costanza ME, et al. (2003) American Cancer Society guidelines for breast cancer screening: update 2003. CA Cancer J Clin 53: 141-169.

8. Husaini B, Sherkat D, Bragg R, Cain V, Emerson J, et al. (2002) The effect of a church-based breast cancer screening education program on mammography rates among African-American women. Journal of the National Medical Association 94: 100-106

9. Park E, Ryu E, Choi K (2003) Influence of participation in breast selfexamination educational program on breast self-examination practice and health promotion practice. Journal of Korean Oncology Nursing 3: 133-141.

10. Lee YW, Lee EH, Shin KB, Song MS (2004) [A comparative study of Korean and Korean-American women in their health beliefs related to breast cancer and the performance of breast self-examination]. Taehan Kanho Hakhoe Chi 34: 307-314.

11. Tae Y, Kim J (2003) Predictive factors of breast self-examination practice of clinical nurse. Journal of Korean Oncology Nursing 3: 122-132.

12. Budakoglu II, Maral I, Ozdemir A, Bumin MA (2007) The effectiveness of training for breast cancer and breast self-examination in women aged 40 and over. J Cancer Educ 22: 108-111.
13. Ceber E, Turk M, Ciceklioglu M (2010) The effects of an educational program on knowledge of breast cancer, early detection practices and health beliefs of nurses and midwives. J Clin Nurs 19: 2363-2371.

14. Sadler GR, Ryujin LT, Ko CM, Nguyen E (2001) Korean women: breast cancer knowledge, attitudes and behaviors. BMC Public Health 1: 7.

15. Champion VL (1984) Instrument development for health belief model constructs. ANS Adv Nurs Sci 6: 73-85.

16. Glanz K, Rimer B, Su S (2005) Theory at a glance: A guide for health promotion practice (2nd ed.). National Cancer Institute, National Institutes of Health, U.S. Department of Health and Human Services. NIH Pub. No. 05-3896. Washington, DC. p. 12-14.

17. Glanz K, Rimer B, Viswanath K (2008) Health behavior and health education: Theory, research, and practice (4th ed.). San Francisco, CA: John Wiley \& Sons, Inc.

18. Lee EH, Kim JS, Song MS (2002) Translation and validation of champion's health belief model scale with Korean women. Cancer Nurs 25: 391-395.

19. Wu TY, Yu MY (2003) Reliability and validity of the mammography screening beliefs questionnaire among Chinese American women. Cancer Nurs 26: 131-142.

20. Wu TY, Ronis D (2009) Correlates of recent and regular mammography screening among Asian-American women. J Adv Nurs 65: 2434-2446.

21. Burns N, Grove S (2005) The practice of nursing research: Conduct, critique, and utilization (5thedn). St. Louis, MO: Elsevier Saunders.

22. Champion VL (1993) Instrument refinement for breast cancer screening behaviors. Nurs Res 42: 139-143. 